\title{
Here You Have To Be Mixing: Collaborative learning on an engineering program in Ireland as experienced by a group of young Middle Eastern women
}

\author{
Shannon Chance \\ Technological University Dublin, shannon.chance@tudublin.ie \\ Bill Williams \\ Technological University Dublin, bill.williams@estbarreiro.ips.pt
}

Follow this and additional works at: https://arrow.tudublin.ie/scschcomart

Part of the Education Commons, and the Engineering Commons

\section{Recommended Citation}

Chance, S. \& Williams, B. (2020). Here You Have To Be Mixing: Collaborative learning on an engineering program in Ireland as experienced by a group of young Middle Eastern women. Published in: 2020 IEEE Global Engineering Education Conference (EDUCON), Porto, Portugal, 27-30 April. doi:10.1109/ EDUCON45650.2020.9125207

This Article is brought to you for free and open access by the School of Computer Sciences at ARROW@TU Dublin. It has been accepted for inclusion in Articles by an authorized administrator of ARROW@TU Dublin. For more information, please contact arrow.admin@tudublin.ie, aisling.coyne@tudublin.ie,gerard.connolly@tudublin.ie.

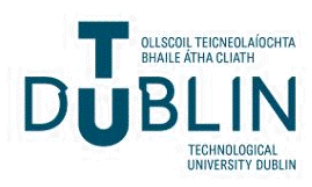




\section{Here you have to be mixing: collaborative learning on an engineering program in Ireland as experienced by a group of young Middle Eastern women}

\author{
Shannon M. Chance \\ Technological University Dublin \\ Dublin, Ireland \\ University College London \\ London, United Kingdom \\ shannon.chance@tudubulin.ie \\ https://orcid.org/0000-0001-5598-7488
}

\author{
Bill Williams \\ Technological University Dublin \\ Dublin, Ireland \\ CEG-IST, Instituto Superior Técnico, Universidade de Lisboa \\ Lisbon, Portugal \\ bwbillwilliamsbw@gmail.com \\ https://orcid.org/0000-0003-1604-748X
}

\begin{abstract}
This research project uses grounded theory to analyze interviews conducted with eight women from Oman and Kuwait. Members of the sample group were studying together at an institute of technology in Dublin, Ireland. The paper reports patterns in 15 interviews collected in the years 2014, 2015, 2016, and 2017 to provide a longitudinal overview of the experience of the learners. During the coding process, three major themes emerged having to do with the experience of learning with others and/or learning in groups. The first theme involved communication within the group and the group's approaches to working together. The second identified specific emotions experienced during group work and motivations participants described having felt. The third centred on learning to navigate diversity, particularly with regard to ethnicity and gender. These three themes underpin recommendations from the authors, intended to assist educators in effectively communicating with diverse student groups.
\end{abstract}

Keywords - PBL, group learning, student experience, study abroad, Middle Eastern students, women in STEM, international, gender, collaboration, engineering education.

\section{INTRODUCTION}

There is a growing consensus of a critical need to diversify the STEM workforce to remain competitive in a global economy. In the US, for example, recognizing the need to attract and retain the most talented individuals to STEM professions, the National Academies has advocated that diversity in STEM must be labelled a national priority [1].

Accordingly, questions of gender and diversity have been receiving attention in engineering education in recent years and both the American Society for Engineering Education, ASEE [2] and the European Society for Engineering Education, SEFI [3] have issued position papers to assist educators.

With regard to gender diversity, although there is a considerable body of work studying the experiences of students in the US and Europe (see [3] and [4] for examples) relatively little attention has been focused upon international female students studying engineering in these contexts. A rare study [4] in the US gathered data from 49 female postgraduate students, of whom 5 were from the Middle East, and concluded that "International female engineers in U.S. graduate engineering programs exist in liminal spaces where their identities are continually being challenged. Through reconstructing inclusion, challenging their invisibility, and reengineering professional efficacy, they transform these liminal spaces to their advantage and persist in their struggles with the challenges they experience".

Given that there have been increasing numbers of female students from Middle Eastern countries training as engineers $[5,6,7]$ both in their own countries and abroad, the authors opted to focus on the experiences of young women from the Middle East studying in anglophone Europe.

The overall research question was: What are the experiences of Middle Eastern young women of collaborative and problem-based learning (PBL) studying engineering in Europe? It aligns with Shavelson and Townes' [8] What is happening? category. The authors aim to examine and interpret these experiences with a view to proposing guidelines for educators working with international students from Middle Eastern backgrounds.

\section{CONTEXT}

This research project uses grounded theory to analyse longitudinal interviews conducted with a cohort of eight women from Oman and Kuwait. Members of the sample group were studying together at an institute of technology in Dublin, Ireland. All participants were practicing Muslims as well as Arabic speakers who had learned English. Interview data were collected from participants beginning in 2014 as part of a larger study of women's experiences learning engineering in various locations in Europe (specifically, Poland, Portugal, and Ireland). The eight women contributing data for this paper were enrolled on a four-year Bachelor of Engineering (B.Eng.) honours-level degree. They comprise the entire population of Middle Eastern women in this cohort of engineering students. This paper reports patterns in 15 interviews collected in the years 2014 through 2017.

\section{PURPOSE}

The authors undertook this line of research to understand students' experiences of collaborative and problem-based learning (PBL) environments. They aimed to understand experiences women have via group projects, paired laboratory assignments, self-directed studies with friends, and other structured and unstructured collaborative learning activities that happen while enrolled in engineering. For this paper, the authors explored experiences of collaborative learning described by the sample group over a period of four 
years at one large, public institution of higher education in Ireland. The research has involved collecting, transcribing, and analysing 15 interviews conducted with this sub-group. Seven interviews were collected in students' first year, one in their second year, six in third year, and two early in the fourth year. Five more interviews were conducted in the last half of the group's fourth year and will be reported in subsequent publications focused on transitions into industry. This report at hand explores the following three sub-questions:

- What has the experience of collaborative learning been like for these women?

- To what degree have PBL pedagogies helped support them?

- Which behaviours of friends, teammates, and teachers have helped these students in learning, and which have hindered them?

In the overall study of which this is part, the authors started by interviewing a broad and diverse set of female engineering students. The primary author travelled to multiple locations across Europe to gather data from students in three geographically and culturally diverse corners of the continent. During the Academic Year 2012-13, she conducted a first set of semi-structured interviews with 46 of the participants. Interviews varied from 45 to 120 minutes in length and were conducted on-campus at an institute of technology in Dublin (Ireland), a polytechnic in Setúbal (Portugal), and a university of technology in Warsaw (Poland). It happened that one-third of the women in the overall cohort of B.Eng. students in Dublin had come from the Middle East to Ireland to study engineering. Because their first-year experiences were significantly different than those described by other participants, the authors chose to conduct follow-up interviews with this sub-group.

\section{APPROACH}

The research reported here used grounded theory to generate understandings of what the Middle Eastern subset of female students experienced and how they experienced it. Using a grounded theory approach allowed findings to emerge from the data, rather than superimposing an existing framework or a priori theory [9]. In Strauss's view, the purpose of grounded theory is to raise generative questions "in order to develop concepts and propositions and to explore their relationships" [10] and to validate categories and findings through an ongoing process of data analysis. Our work involved transcribing the interviews, reading them in their entirety, and then conducting open, axial, and selective coding of transcriptions [10]. Literature the authors have reviewed on pertinent topics is reported elsewhere [11].

The interviews were gathered in such a way as to be appropriate for analysis using grounded theory or its close associate, phenomenology. As such, open ended dialogical interviews were conducted. Topics were raised by participants and not by the interviewer. First-year interviews started with the question "How have you been getting on here at the institution?" and subsequent interviews asked "How have things been going since we talked last?" In this way, the research team sought to discover what participants held to be important, rather than to suggest any pre-determined topics or themes.

\section{OUTCOMES}

During the coding process, three major themes emerged having to do with the experience of learning with others and/or learning in groups. The first concerned communication within the group and the group's approaches to working together. The second identified specific emotions experienced during group work and motivations participants described having felt. The third theme centred on learning to navigate diversity, particularly with regard to ethnicity and gender.

\section{A. Communication and Approaches to Group Work}

On the theme of communication and approaches to group work, participants discussed forming groups, dividing work, times they had experienced effective collaboration, times they had experienced ineffective collaboration, providing leadership, and seeking advice or arbitration from teachers. They expressed clear desire to have Irish students on their PBL teams, noting it was preferable to also have at least one other person (female or Arabic) on the team who they could more easily connect and communicate with.

In situations where the woman was alone - as the only female or the only non-Irish person on a team-she often felt ignored, outnumbered, or unable to fully develop and explain ideas she was trying to pitch to the group. Having someone who shared a minority characteristic allowed her to bounce ideas off someone else and achieve an initial level of buy-in before presenting an idea to the larger group. This gave her confidence and the chance to develop ideas better. At firstyear, one participant noted:

F01a: for our [mechanical] project, there was two girls and two boys. And this, I think, this was helping me. Because we were having different skills from them and then it comes together to form the right skills for such project.

In cases where the participant was the sole minority student in a team, particularly in the first couple years, her ideas usually fell on deaf ears and she felt forced to go along with the crowd, even when the team failed to consider enough options or to refine its work. One participant identified many bad experiences that happened prior to fourth year, but by graduation she announced with glee that she actually now preferred working with boys. In her third year, she had said:

F07b: Actually, I feel like I hate them [laughs]! Yeah, I feel like just want to go with my friends - the girls-and work with them. I feel free, actually, when I'm sitting with girls. It's more than when I'm sitting with boys. Because boys when they said [an initial idea of] something they want to build, they go straight. This is the idea. No one can change it. When I speak, they see, like, one girl: "No, we don't have to take this idea. So what's the next step?" So they hide me sometimes. ... So when they start saying that, I feel like, inside me I, "I will not say anything. I just, I will be quiet and I will listen to them. And if there is something wrong, I can say my idea again."

At times, she had been doing projects as the only woman, on a team with eight men. Having an Arabic male peer on the team helped her.

F07b: I explain [ed the concept] for him, for example. And he said, "Yeah that is maybe [the] right idea." And he will add a little bit. For example, [some] extra idea for [enhancing] my idea. So that's what makes a bigger idea 
to translate to [our] Irish [teammates], and maybe they will accept it. Because it's my idea and his idea together, it's not just mine.

Similar to F01a above, another first-year student also described some level of effective team work. This happened across her group's six-week design project:

F03b: I had a Filipino girl ... and [we] were two girls and two boys. So whenever we have something like, "[Hazel] let's tell them this," or like that. Yeah, it was much better. And we were like, "Do this. Let's do this. Let's do that." And we could understand each other better that way. I think that was a good group. ... at the beginning of it, it was really good. Because we were all together, working together.

Recruiting others to join a team often proved difficult, and participants had often fallen onto team of whoever was left over during the team selection/assignment process. They didn't feel comfortable approaching male Irish students and asking to join their groups. A first-year student explained when selecting teams:

F06a: we'll just pick ... Arab people, of course. I will not go and pick, like, Irish people, because I just don't know them. And it will be easier to speak.

Several appreciated when teachers composed the groups in ways that balanced skills and abilities, because they did not like being on teams that were homogenous. While forming a group was easier with same-language students, they experienced difficulty on teams comprised solely of international students. The described difficulties on teams with poor English, as well as all-female or majority Arab teams. These groups lacked diverse enough skills, perspectives, interests, and/or physical strength, they said. With regard to primarily-Arabic groups, they cited problems of not getting to practice English and of experiencing freeloading (wherein even close friends assumed the other would do the work and take up the slack). Although they socialize with a small group of Middle Eastern women, almost all preferred not to work on teams with these women after second year. Their desire from the outset was to work in diverse teams and communicate in English - developing such ability was a primary reason they cited for coming to Dublin to study engineering rather than staying at home to do so. In fact, the need to practice and work in English was frequently cited in all years. Here in a third-year interview:

F05b: I have my friends, but I want to be more with the Irish people so I can improve my English language. [It's] one of the reasons I choose to study abroad, instead of studying in ... my home country.

Interaction with Irish peers was highly valued where it occurred in the university setting. A first-year student explained:

F03a: We didn't interact a lot with the Irish people in Foundation Year. But in this year ... all of our classes are with Irish students and we are not a lot of people from Arabic countries. Less than 20, or less than 30 ... and we were like 160 students in this course and it was a good to like sit with Irish people in our ages and talk to them and do projects with them. ... I think it's good not to have a lot of people from your same country or region, so you can get to know other people's ideas and things like that.

However, getting to the point where they felt comfortable working in diverse teams and communicating in English took quite a bit of time and effort. Some did not feel comfortable working with primarily-male groups until final year and most did not take the lead on getting themselves into such groups, but rather waiting to be assigned to teams with Irish students. Participants recalled ineffective team approaches they had encountered. As noted above, they contended with slack team mates who were under-contributing or underperforming and at least one participant admitted to being guilty of the same on occasion. They described teams rushing or underdeveloping ideas, and teammates who resisted rehearsing or refining the final product. Their techniques for dividing work had both positive and negative aspects: in some cases the division of tasks was too strong and the participant failed to learn a wide set of skills. One recognized this as a problem but another continued the behaviour throughout her studies, focusing only on the portion of the project assigned to her and avoiding engagement or responsibility in areas assigned to others. The student quoted above also said at third-year explained:

F05b: And it was a group of four students. We split the project into four parts, and everyone has taken a particular part to do. ... [And the teacher] would say, "Do something, show me some progress. " And I'm like, "I don't know what to do, because we are working as a group, so I'm waiting for my colleagues to finish working with their parts. " And then, "Do something, show me some progress"... because he's like, you know, "It's all about self-learning."

Fortunately, the students also described effective team situations and many instances where good decisions were made by their teams. Participants noted the importance of being able to ask questions, get full and complete answers, and find peers who wouldn't mind being asked questions. They wanted to develop ideas together and they valued being on a team that made decisions collaboratively. They described getting advice/critique and gaining ability to communicate using English. They expressed empathetic understanding when others needed to miss a class or a team meeting and expected the same level of empathic understanding in return.

It was rare for these women to volunteer for leadership roles, although one seemed to be viewed by peers as an implicit leader who could be relied on to check the work of others, because her work was seen to be of consistently of high quality. Within this small social circle, some were more likely to organize gatherings outside school hours than others. Some wanted to study alone so they could concentrate, while others enjoyed studying with peers on weekends. Their informal group study sessions were more frequent during first year, when the eight had a common curriculum. As the years progressed and they developed specialities, there were fewer occasions when these Arab-speaking women were enrolled in modules together.

Their interviews describe the importance of self-directed and peer-to-peer learning. Most participants in this sub-sample relied on the internet and on peers to help them understand important concepts. They tried to manage group dynamics themselves, going to the teacher only in cases where they had been heavily exploited by a partner or teammate. They rarely asked the teacher to arbitrate or give special consideration in grading to account for lop-sided contributions. Although some instances of doing so were described, in such cases the teacher was highly trusted and explicitly expressed interest in supporting students. 


\section{B. Feelings and Motivations}

Participants described a range of feelings, some positive and others not. They discussed feelings and situations that motivated them to persist. Positive feelings had to do with excitement and joy, hopefulness, and respect for diverse approaches. One third-year study, in thinking back to first year, stated:

F05b: I was involved with a group of Irish people and they were very kind and friendly and helping me to understand the subject and they said, "If you have any questions you can ask us." And, "We can answer your questions. If you face any difficulties with the things you don't understand."

Then overall it was fun, and I learned the things, which I didn't do before.

For the one student who exited engineering before earning a degree, group work had nevertheless provided positive experiences. At second year she stated:

F08a: They're just so nice and I feel so lucky that I have been put in such group. Though I wish they were strict with me. But they weren't - they were just nice.

Negative emotions included feeling stressed or unmotivated, lazy, or fearful of failure. This group described instances of feeling alone and excluded; other than loneliness and exclusion, most of the other negative feelings (stressed or unmotivated, lazy, or fearful of failure) were also described by the larger sample of women in this B.Eng. course, and are likely to be shared by most engineering students. Many of the Irish women in the larger sample did not describe feeling alone or excluded - in fact most described the opposite, reflecting high levels of acceptance and feelings of belonging across their engineering studies.

In the specific case described below, the Middle Eastern participant was in a team with six other women, and was the only one who was meticulous about attending meetings, completing work, and submitting the first assignment. She took her work quality seriously. At third year she explained:

F03b: Once, we had the power assignment. It was like, you have an individual report and a group one, and the group one was supposed to be all the same. So I was asking them to come and do the work, "We'll do it together." And we were an all-girl group, and they didn't show up. And I kept doing the group work, all by my own. And I finished it and then I sent it to them, "This is our group work" and "submit that one." So the next time we had a group report, I went to another group because I was not going to do that anymore. ... It stresses me out. ... the week went by and I didn't get time to study at all, I just finished my eight assignments and that was it.

Following this negative group-work experience, she consciously made her way into team that had a better work ethic, and her experience improved.

Under the sub-category of motivations, participants described seeing the benefits of teamwork, not wanting to let others down, and recognizing the need to work with others in future jobs. At third year, the following participant said:

F02b: In the first year it was a little bit hard for me to accept [the small number of women in the course]. But now, I understand. Here, you have to be mixing. Even with Arabic guys, or Irish guys, or whatever. You have to be mixing here. Because also in engineering, you'll see, there's not too much women in engineering and there is much, much of boys. And we have even like, one girl in groups of boys. And that's like-it's fine now for me to work with the boys.

They didn't want to let others down. Stated at third year:

F01b: I do my part directly because I don't like people being late because I didn't do my work. So I [always] finish it very quickly and just give it to them.

This holds true for the participant who never enjoyed engineering and left the programme after second year:

F08a: I didn't choose anyone [for my group] because I

know I'm too lazy and I didn't want to let anyone down, so I just didn't speak up.

The other seven participants all stayed on to earn engineering credentials from the institution. During their studies they experienced panic and success as most students do. Here, at first year:

F05a: When Week 6 came, I was kind of panicked. How can I present, the presentation, in front of [40] people? ... I asked [a female Irish student], to help me with presenting the presentation, and she was very helpful. So we divided the work between us.

\section{C. $\quad$ Navigating Diversity}

Topics raised by participants that the research team coded under the theme of diversity involved the following subthemes: forms of social support, being different, widening circles of friends, gender mixing, and coming to terms with gender differences. The biological family formed the core of these women's support networks. Families back home were important, and all except one participant had family members enrolled at this same institution or already residing in Dublin before she moved here (a sibling of the remaining one subsequently enrolled at the institution, as well). These prior residents provided valuable advice and encouragement to our Middle Eastern participants. Embassies also provided support and coordination, and helped the participants find housing, often with host families. For many of the Omani women, host families in Ireland became an essential and ongoing form of support. Within the host families, they usually had other Arab girls to interact with, as well as Irish host 'moms' and other Irish family members. A quote from first-year summarizes:

F02a: Sometime because my friend [another Omani girl living in the same host family to] take the subject before I take it, when we sit together, she told me what happened to her all day and I tell her what happened to me. And we share the idea, sometime. .... But ... outside the home, she takes her way and I take my way.

Participants came into the engineering program already knowing and keeping in touch with some international students (female and male, Arabic and otherwise) who they had previously studied alongside while learning English in Dublin or during the preparatory Foundation Year provided by the institution for many of the international students, particularly those who had not completed Ireland's Leaving Cert (examination prior to secondary school graduation). The sample group had limited experience of working in groups during Foundation studies, and no experience of group work related to engineering prior to entering the institute. Group skills had to be learnt in their B.Eng. course, because the first year involves three major group projects that collectively span the year. Engineering students at this institution also experience labs that are conducted in groups or pairs. 
Members of this sample described the frequency and scope of group projects increasing over the years. Conversely, the number of women, and particularly Arab women, in their respective program decreased over time. When asked at third year if she felt she belonged in engineering, one student explained her perception had shifted over time:

F02b: In this year, yes. But in second year, no. I feel like this, because in this year, in my group, it's just me. No girls with me. Just there is [one] Irish girl with me. And when I went to her and start to speak to her, it's like [she] ignore me. And that's why I hate to be in this group. ... But it's okay because there are boys from my country and I can connect with them. ... [First year] I was in boy group, and I'm just keep myself. Like, [I waited to] see what goes on around me. And after we start building, I have a big idea what's going in this project. ... [It was hard for me] because it's first time for me to do the project, and also because I'm only girl in that group.

Their interviews show that they felt acutely outnumbered at the start of their course, discovering just 25 female students in their class of 180 . During a first-year interview, one participant explained:

F06a: Well, back home is different. Girls who do engineering, are a lot. Back home, a lot of girls [do engineering].

As noted above, most Middle Eastern participants described instances of feeling alone and excluded. Initially, they found comfort working on teams with other girls present, and many were given this opportunity due to a concerted effort by the teachers who were facilitating the projects. In two of the three projects, teams were assigned rather than self-selected, and after the first round of projects, the teachers aimed not to isolate any female as the sole woman on a team. This was not always possible to achieve, their teachers said, and in many instances the women in our sample found themselves in a minority position. By third-year:

F07b: We work always in groups with Irish girls and boys-so we need to mix with boys and girls and we need to talk with them because if we just don't talk with them we would feel lonely and we can't connect with them successfully. ... We are five-four boys and one girl [laughs]. Because [the two other Arab girls are on a team] together, but me, I'm with all boys, no girls. I tried to be [on] a girls [team], but this is my group.

... I was worried about those things when I was in first year. But now I'm [on] the fifth year for me in Ireland. So that's a change now. Like I can connect with other people and it breaks down other things. When I go back to my country-like, for example, in my country-we can't sit with boys. Like it should be like sitting with girls just. But here in college, it must be with girls and boys. So we should go ahead and like try to break some rules here [laughs]. ... There was some difficulties about that, but we should like speaking [with others in English] and learning new things. Because if we [are always] still thinking about the same roles like I have in my country, I can't do anything here. Just, I will not learn anything new. So I try to mix.

For her, participating in a women's society helped, and although she had no classes on the days this organization met, she made the lengthy commute to the meeting. During her third-year interview, she added:
F07b: Actually you know the Woman's Society of Engineering? Now, just for this year I am a member for them so I meet a lot of girls, actually. They are friendly and some of them [are] in fourth year doing civil engineering and we can ask them for anything like, because they have all the comment from last year and they can show me what we should be doing for this subject, and this subject, and this subject.... I find you can get close to the girls and speak about anything that's belong[ing] to college, teachers and subjects. You can share a lot of things that [are] happening in college.

In addition to the support from diverse women described above, Arabic women had provided an essential form of support in early years. During this period participants in the sample had been developing skills and intuition that would allow them to communicate with a wider group and learn to effectively request help. At second-year:

F08a: When I came here, I only ha[d] one Arab girl with me, and that is [Sunita]. All the others are guys. But then, you have to start talking to the males. Because, when you need help ... like if I and [Sunita] got stuck-I'd ask others. And yeah, they'd be really willing to help.

Social interaction with Irish students was rare and did not occur beyond the campus, except in host-family settings. When asked "Do you have friends who are actually Irish?" the second-year engineering student quoted above explained, just before leaving the program:

F08a: No. I didn't manage to be friends with any Irish women. Like, you know [Grainne]? We used to speak at first but then we just all of a sudden stopped talking and that. Yeah, [Grainne] is the only Irish woman I know.

During ten of the 15 interviews included the research study reported here, the participant identified benefits of working with girls. Three interviews included descriptions of times their all-girl teams grappled with having what they saw as an inadequate range of physical abilities and prior experiences in engineering.

Social and academic interactions expanded over time from: (a) finding initial comfort in communicating with Middle Eastern women, to (b) later comfort interacting with women from other places, then to (c) comfort interacting with more males from the Middle East, and then lastly to (d) comfort working with more diverse groups of men. Most participants develop aversion to working on teams heavy with international students. At first-year:

F06a: Unfortunately, I was working with three, from Kuwait, with me. So we're four from Kuwait. So then this semester I worked with Irish. Different people. ... [When] we were four from Kuwait, we always speak in Arabic. And we never speak in English. ... Like everyone is depending on the other to do the work. And they would certainly be like, "She will do this. I know she will do this." And then they will not do. But when I work with Irish people, everyone does their own work, and everything is okay.

The same participant said at third year:

F06b: I don't want to be so rude, but most of [the Arab students] want you to tell them what to do. And then they just come and they just do their stuff, or they do their stuff very late, and most of them are like, huh!, the worst I've seen, so I need to go and, and re-do them again, whichwe don't have time to do this. 
It was in the deep conversations with close female friends from the Middle East, however, that some of the richest selfdiscovery emerged.

F08a: [And now] I know who I am. I have my own opinions and things and not just because like, say, in Islam, people are separated in different groups. I don't know if you do this. So basically, my friends, the Omani ones, they had, like wrong [stereotypes]. And they discussed their religious views on certain things we have, and they don't have. I explained to them that I actually started to search, "Why I'm doing this?" and "Why I'm doing that?" Like, I still want to learn more ... I want to make sure that I'm not just following my parents. And ... it was great experience for them to correct their views on [their wrong assumptions]. And also it's like they made me notice that I'm missing knowledge on why I am Muslim. So I want to learn more about that.

The need for diversity became quickly during first-year: F01a: And then my partner was from Oman too, so, we couldn't figure it out. ... We have the same problem-that he didn't do any stuff related with this subject-like me too. So we were having the same problem. We didn't figure it out. ... That usually happens, I don't know why, but, that we'll not co-mingle. Like usually we're-Arabs will have their section, and groups-unless the teacher makes it.

The need for diversity was well-recognized by third-year, despite the discomfort it could cause.

F02b: Maybe we feel more comfortable when we chose our group because you know what these will do and how these will do in your group and maybe they will work or not. This is good. But when we meet different students every time, I think it's much better to have an experience and you make a point, because when we go and have a job you have to also work with a group you didn't know. So I think it's a good experience to work with a group you didn't know.

For a couple participants, men from the Middle Eastern became close collaborators. One developed a friendship with two males of Middle Eastern descent (who were raised in Ireland and who she referred to as 'honorary Irish'). Another was bailed out of a failing project by a married Saudi man, whom she was not permitted to make eye contact with or speak socially to. Nevertheless, when he saw she was in trouble and lacking team mates, he developed a plan to include her on his team. They secured approval to add her to the team from the teacher, after developing a plan to catch her up on the necessary subject matter using on-line screen sharing software. In this way, the Saudi student was able to tutor the Omani female without violating his cultural rules. Before coming to Dublin this female participant had rarely spoken with males, and she said this was by choice and tradition.

F08a: back home I've been to a mixed high school, but I didn't use to interact with males. Like, it's just, I didn't used to. But here I ask a lot. I'm not afraid to ask for help, even if they were male. ... I've this classmate that is from Saudi. He is really, really, really kind. Like, he always, after every lab, he goes around each and every person and then he's like, "Do you need any help?" Or like, he's so, so kind. Honestly, he took a big burden off of my shoulder. .... I do believe that God had put kind people in my way to make this journey tolerable, because honestly, I would have lost my mind if I didn't have anyone to help me. ... He just loves to help. And when I say "thank you" he doesn't like it, because he's like, "Why are you thanking me? God has put me in your way. You should thank God, you shouldn't thank me." And, he's so humble.

Familiarity helped increase comfort communicating across gender lines over time.

F08a: I also have like other male mates, that they help me like almost all the time ... from Saudi, Kuwait, and some of them are from Oman.

They also sometimes found the courage to take a stand. This third-year student explained:

F03b: And I know that our Middle East boys don't think we're right and they think we don't know anything. But this year, because we studied together from Foundation Year until now, he was okay with telling me he was wrong. Because I know him from Foundation Year, so he told me, "No, you were right" and he was wrong.

A couple participants benefited from having a host brother studying engineering. Four of the students developed close and supportive relationships while staying in two specific Irish host families. Described during first-year of the B.Eng. course:

F01a: the boy [in the host family is] really, really good at mechatronics engineering. He did RoboSumo and he won. He was the first year. And so, he's naturally, he's really good at these things. So when we talk about these things, the host mother just sits and says "What are you talking about!?" [laughs] ... my first year, I was living in a different family. And I didn't feel comfortable there. And then I moved to this family and actually I don't want to move to another place. ... I said to them, "I'm really comfortable here. I don't want to be feeling differently from this."

They were just learning to work with male students, as reflected in this first-year interview.

F06a: We've never worked with guys before, even in schools back home. We have separate schools for girls and boys. So I've never even sat next to a guy in a class. But, when I came and did the Leaving Cert, I got used to like, being to sit in the class with guys. But I didn't get the chance to work with them on projects and stuff, because I didn't have these sort of [group projects before I came into engineering].

Beyond host-family settings, participants rarely interacted socially with Irish students. They were more likely to describe social conversations with taxi drivers and people in shops than with Irish students beyond the host family. Nevertheless, participants provided extremely detailed descriptions of their early academic interactions with Irish students, and particularly with male Irish students. These descriptions are what qualitative researchers would describe as thick, rich, and highly phenomenological. Their tendency to provide such high levels of detail about interactions that mainstream/Irish students would see as mundane suggests that the experience of "working with boys" was highly significant. It was new enough that the participants mentally registered and stored in memory detailed information that would normally be lost or overlooked if and when the situation was seen as commonplace. The following participant was on an "all-girl" robot-building team that had two Omani and one Irish girl. At first-year, she described interaction with the other, "all-boy" teams. 
F03a: In Week 6, we had the Race to the Wall. And that week, we couldn't get our robot to move. It wasn't moving, at all. And we went to the canteen and we found the boys from our class. And we told them, "Can you help us?" And he said, "Ok, I'll try." And he tried and tried [excitedly] and he did. And he said, "I don't know what's wrong." And, the other boy saw our circuit, and he said, "Oh, your circuit is different from our circuit." That's so, "I can't help you." And I told him "Ok, it's not a problem." Like, "we'll get [it]. We'll do something." And I sat with my friend in the canteen, and we tried, tried, tried, to make it work. And it was moving as we wanted, and then the boy who saw our circuits came, with his other friends, like six boys, and he sa[id], "Did you get the circuit to work?" And we said, "Yeah, it's working now." And they sat all around us [laughing] and we sat together. And, we were, like, chatting, in the canteen. "Oh, how's your robot?" Yeah, yeah, oh "What group are you in?" Oh, like that. And then I put something, and my robot fell. And, I broke one of the motors, before half an hour from the race. ... And they said, "What just happened? What did happen?" And like, "Do you need help, or anything?" I said, "No, no, I'll get it to work" [laughing]!

The interviewer asked: "Can you tell the boys apart? Do you know their names?" At the end of first-year she said:

F03a: Now I know their names, but before, no. They're all-like what I see is they're all-alike [laughs]. They would have yellow hairs, or something like that [laughs]. Yeah, so, I don't know then. But now I started to get to know them and to know their names. Because now, even in our classes, we would joke around like that. And so we're more together now. We know each other better now.

Throughout the years new students joined their programme from other streams. At third-year the student quoted above stated:

F03b: I know [many of my teammates] from my first year and until now. So it's not that hard to work with them, because we already know each other. But this year they combined us with another program, so I am still getting to know the new classmates.

They had closer communications with students from the Middle East and other non-Irish places, and generally saw these as beneficial. All participants identified productive and supportive collaborations with international students, although about half also expressed reluctance to join teams that had many non-Irish students on them where they perceived lower level of engagement, reliability, and ability to write and speak in English. Even these reluctant students, however, described many good experiences with international students, such as a male met during Foundation year, prior to joining the institution. At first-year:

F05a: Two or three weeks ago, I think, I was absent... because I was sick. And then I came here to the college and then I saw [Carlos] and I told him, "What's missing, and what can I do?" And he said, "If you want, we can go to the library and then I can show you some works that you can do." And then, we spent almost two-and-a-half hours together, doing the [work], because he wants to help me to catch up. ... Then he said, "Do you understand? If you do, do one of the questions and then show me. "Just, he wanted to make sure that I have understood and then he's going to show me the solution for that question.

\section{FINDINGS}

In speaking with these eight Middle Eastern women and learning about their experiences in Ireland, we gained insight into how they communicated and structured their group work, what they sensed and felt, and how they widened their circles of collaborators and friends over time. We developed greater understanding of 'intersectionality' as we discovered what it was like to work with students from different language- and culture-groups, first learning to communicate at basic levels and eventually learning to work effectively on complex projects with male peers. At least seven of 15 interviews described greater ease in connecting with girls than boys. Participants had been surprised to find such a small proportion of women in the course they joined, and they felt obliged to speak with male students from the outset. A number of stressful and disappointing experiences with boys were described - most where the participant felt ignored or overlooked - but the frequency of these subsided as their familiarity and confidence grew.

Several participants described what they saw as inherent differences between boys and girls. They mentioned the ease of connecting with other girls, but also the need to have team members with prior engineering experiences and greater physical strength -qualities the participants associated with boys more than girls. Nevertheless, there were only a few comments expressing outright gender bias. This one from first year:

F03a: I wanted to take Mechanical before, but I think it's not suitable for me. I think it's not suitable for girls. ... There's girls who take Mechanical, but I think it's not suitable for a girl. So I don't want it.

Even though there was a preference to have other women on the team, particularly in the early years, there was not a sense that women were inherently better or worse at engineering. In fact, participants did not want to be on all-girl teams and this preference emerged quite clearly in their first year. They did not see women as inherently more organized or inherently better teammates or collaborators, even though they did see women as easier to talk/communicate/connect with. At thirdyear this participant responded to the interviewer's question "So ... when you have the Irish boys and girls on the team with you, it helps make it easier?"

F07b: Yeah, boys with girls, I find. Because maybe girls know something about that subject and boys excellent in another side. So girls can make a nice project or nice idea.

\section{RECOMMENDATIONS}

As a result of prior analyses involving these data, the authors generated recommendations to help educators do a more effective job communicating with diverse students. These are reported fully elsewhere [3] and summarized here. Instructors are recommended to:

Consider approachability. Project a sense of approachability and availability.

Facilitate peer learning. Promote collaborative learning by encouraging interaction and helping students conceptualize their cohort as a team and view their classroom as a laboratory for learning together.

Reduce distance. Break down the distance between student and teacher. Discuss when and where and how students can 
get various types of guidance and mentoring. Encourage students to take risks and see failure as a step toward success. Consider language. Check for communication and 'tacit knowledge' issues. Pose some questions to check that students understand basic background and foundational concepts and that they can connect new ideas to prior knowledge or experience. Understand that while they may have foundational knowledge, they may not be making connections that educators or native-speakers make implicitly.

Balance teams. Recognize that minority students typically feel uncomfortable asking mainstream students to be in their group. The authors recommend providing group assignments where the group is selected by the instructor, as well as opportunities to work in student-selected project groups. Monitor student engagement by observing teams in action and then provide feedback on team dynamics. Model good decision-making practices whenever possible and explicitly describe best practices with regard to collaborative work.

\section{VIII.CONCLUSIONS}

Participants in this study often felt their ideas were ignored by teams that were predominantly male. They valued having someone more like themselves - whether female or speaking their own language - to bounce ideas off before posing them to the whole team so that the idea would be strong enough to be taken seriously.

As a result of observations with these students since 2014, the authors are finding it helpful to diversify teams as much as possible. When assigning groups, they now take into account gender, national/non-national status, attendance records and/or performance on past projects. They aim to have students work on projects with many different students during their first year. They assign teams for diversity as so as not to isolate anyone as the only female or only minority student in the group. When students are unfamiliar with each other, the authors/tutors provide icebreakers to help them get to know several people before assembling their teams.

\section{REFERENCES}

[1] Committee on Science, Engineering and Public Policy, Division on Policy and Global Affairs, National Research Council, Expanding Underrepresented Minority Participation: America's Science and Technology Talent at the Crossroads. Washington, D.C.: The National Academies Press, 2011.

[2] American Society for Engineering Education, About, retrieved from https://deansdiversity.asee.org/about/, 2017.

[3] K. Beddoes, S. Ihsen, M. E. Vigild, J. Mitchell, G. Panther, M. Murphy, B. Williams, and L. M. S. Ruis, SEFI Position Paper on Diversity, Equality and Inclusiveness in Engineering Education. Retrieved from https://www.sefi.be/wp-content/uploads/2018/05/Diversity-2018links.pdf, May 2018.

[4] D. Dutta, Sustaining the pipeline: Experiences of international female engineers in US graduate programs. Journal of Engineering Education, 104(3), pp. 326-44, 2015 Jul.

[5] P. A. Koushki, H. A.Al-Sanad, and A. M. Larkin, Women engineers in Kuwait: Perception of gender bias. Journal of Engineering Education, 88(1), pp. 93-97, 1999 Jan.

[6] M. A. Elhussein, D. Düștegör, N. Nagy, and A. K. Alghamdi, The Impact of Digital Technology on Female Students' Learning Experience in Partition-Rooms: Conditioned by Social Context. IEEE Transactions on Education, 61(4), pp. 265-73, 2018 Jun 11.

[7] D. Kirk and D. Napier. The transformation of higher education in the United Arab Emirates: Issues, implications, and intercultural dimensions. In Nation-building, identity and citizenship education 2009 (pp. 131-142). Springer, Dordrecht.

[8] National Research Council. Scientific research in education. National Academies Press, 2002 Apr 28.

[9] J. M., Corbin and A. Strauss, Basics of Qualitative Research: Techniques and Procedures for Developing Grounded Theory. Thousand Oaks, California: SAGE, 2008.

[10] C. Grbich, Qualitative Data Analysis: An Introduction. London: SAGE, 2013.

[11] S. M. Chance and B.Williams, Preliminary findings of a phenomenological study of Middle Eastern women's experiences studying engineeering in Ireland. American Society for Engineering Educ. Salt Lake City, Utah: ASEE. 2018. 